\title{
Techno-Stress in Online Education - An Emperical Study
}

\author{
Ms.Pratikhya Priyadarshini ${ }^{1, *}$ Dr.Amarendra Pattnaik ${ }^{2}$ \\ 1.Assistant Professor-I (Law), School of Law, Kalinga Institute of Industrial Technology, India; \\ pratikshya.priyadarshini@kls.ac.in \\ ${ }^{2}$.Assistant Professor-II (Management), School of Law, Kalinga Institute of Industrial Technology, India; \\ apattnaik@kls.ac.in \\ *Corresponding Author Email pratikshya.priyadarshini@kls.ac.in
}

\begin{abstract}
Novel corona virus has impacted human life enormously. The fight against the pandemic will be long and sustained. WHO has rightly advised all countries to ensure social distancing to keep the virus at bay. In India, Governments both at the centre and the states, have been enforcing social distancing among the citizens. This has adversely affected all the sectors of the economy. Education sector is no exception. All educational institutions including coaching centers have been ordered to stop classroom teaching. To ensure continuity of teaching-learning, most of the educational institutions in the private sector, have shifted to online teaching. Digital technology has played an instrumental role in connecting the students and the teachers. The pandemic has fast tracked the adoption of digital platform in teaching. Prior to the pandemic, virtual classrooms and blended learning was a far cry. But now it is a new normal. Both the teachers and the students have quickly adopted and have adapted to remote teaching-learning.

Online teaching has brought in many benefits, but there are some side effects as well. One of them is how it has affected the stakeholders physically and mentally. In this paper the authors have tried to analyse the impact of technology on the two most important stakeholders in the educational value chain, namely teachers and students. Data proves that digital platform has adversely affected them not only physically but also mentally. Based on the findings, the authors have given few suggestions to reduce techno-stress which is incidental to online teaching-learning.
\end{abstract}

Keywords: Techno stress, Virtual Classrooms, Online teaching, Blended Learning, Corona Pandemic.

\section{INTRODUCTION}

Since Corona pandemic arrived in India in mid of March-2020, life has not remained same. It has affected everyone in its own way. Initially, people were dismissive about the enormity of its consequences, but after learning the havoc it caused at USA and some European counties, people realized that this infectious disease is not something that they can wish away. Corona spread like wildfire and caught developed nations unprepared. On the other hand, India walked the cautious path of "Prevention is Better than Cure". It was quick to adopt shut-down and lock-down ${ }^{1 \& 2}$ as two potent weapons to keep Corona spread at bay. Social Distancing and wearing of mask were strictly enforced. Social gatherings were disallowed and violators were taken to task. Concurrently, Governments at both the centre and the states scaled up the health infrastructure to deal with the spread of the disease. Hospitals were earmarked to treat Covid patients and people involved in providing public service were declared Corona warriors. Public servants like doctors, nurses, police, media persons etc were given state recognition and compensation for their stellar service to the humanity without fearing their own well being.

Corona pandemic affected all sectors of the economy ${ }^{3}$. Education sector was also affected. States declared shut down of educational institutes and coaching centers to prevent crowding and consequent spread of the disease. This decision put a sudden brake on class room teaching and derailed the traditional way of teaching-learning.

Schools and colleges, particularly those in private sector quickly shifted to the online mode of teaching-learning, though they were well aware of its limitations. Neither the teachers nor the students were 
ready for such a transition. But in the absence of any other alternative, all shifted. It was comparatively easier for the young students to shift as they are tech savvy. Teachers faced initial adjustment issues but slowly adapted to the new way of teaching. Aged teachers, who had never used technology also learned the nuances of technology and tried to cope with the new mode of teaching.

But this transition brought stress to all the stake holders in the education value chain, particularly the teachers and the students. Every newspaper carried the impact of the pandemic on the education sector. The following are some sample news items carried out in the leading newspapers.

In a news item in The Hindu ${ }^{4}$, NSO highlighted the wide disparity in access to online classes. There is inequity between urban and rural population and also inequity across economic segment. While in some urban upper class internet access is $70 \%$, in many rural pockets where people are generally poor it is less than $5 \%$. There are news reports that some students of Bonda tribe in remote part of Odisha trek more than five kilometers up the hills to get internet signal (Times of India, $17^{\text {th }}$ Sept) ${ }^{5}$. Most poor people are struggling with livelihood and can't afford a smart phone for their children. There are some extreme examples of children committing suicide as these academic necessities are not available with them.

In this context Delhi HC, one of their recent judgement has directed all the schools to provide digital accessories needed to attend online classes (Times of India, September 19,2020) ${ }^{6}$. The court said , private schools which are mandated to provide free education to $25 \%$ of the EWS/DS of the society are obligated to provided the gadgets to access the classes, else it will be considered violation of Art-14 of the constitution and the RTE Act-2009.

Online classes have brought smiles on the face of a segment of students. Children who are physically challenged or have altruist condition, online classes has come a boon. They are able to attend classes from the comfort of home and care of their parents. Even those who are temporarily immobile because of accident are able to attend classes. Moreover, it is reported that students who are shy and prone to be bullied are more happy studying from home and are active in class participation. Children from EWS who get admission at good schools based on reservation used to be sidelined and ostracized by other students. Now they are happy studying online. All these have been reported in a leading newspaper (Times of India, $18^{\text {th }}$ Oct $)^{7}$
On the other hand, students who are sensory challenged have been adversely affected by the pandemic ${ }^{x}$. When they were in school they have a proper support systems (scribes, readers, escorts and attendants) but now the children are entirely dependent on their parents for their everyday schoolwork. All the parents are literate and hence are not in a position to help their children. There are 21 different types of disabilities and each type need a specialized human support system. Swabhiman, a community-based disability rights organisation in Odisha and National Centre for Promotion of Employment for Disabled People (NCPEDP), a disability legislation unit of eastern India have conducted a research on the subject and have come out with the findings that this segment of the students have been worst affected by the pandemic.

Another news report narrates how children in the poor segment are stressed because they have no access to technology like their rich counterparts. Moreover, they are not getting the mid-day meal as the schools are closed (Times of India, $16^{\text {th }}$ September $29,2020)^{9}$.

In another news article (Financial Express, 20 ${ }^{\text {th }}$ May 2020) ${ }^{\mathbf{1 0}}$, educationists are unanimous that the future lies in blended learning and smart class rooms. Even when schools will open, not all students are going to come to the class room. So, teachers have to be teaching two category of students - those who come to the class room and those who wish to learn online. This will add more workload on the teaching community and will be a challenge both physically and mentally.

In an article "how Principals prepared for their toughest test ever"11 in the Times of India, interviews have been conducted with school principals to find out how teaching-learning has been affected post-pandemic. Most of the principal accept that the pandemic caught them unprepared but they have been able to transition to an online mode with the co-operation of the teachers and the students. While it was easy for younger teachers to shift to the new platform swiftly, teachers in the age group of forty and above faced challenges.

There are reports of harassment of the teachers on the digital platform (Times of India, September 22, $2020)^{\mathbf{1 2}}$. Strangers getting into classes, anonymous lewd screen pop-ups and students giggling to these happenings are common. Female teachers are being targeted more by such digital rioters. Neither the dress code nor discipline can be enforced when students are learning from home. The informality at the students 
end in their own home, many times arising out of small living space, is a cause of stress to the teachers.

Ophthalmologists and Optometrists are unanimous on the observation that online education has increased the screen time of the students and teachers. This is adversely affecting their eyesight which includes headache, eye fatigue, blurred vision and eye irritation. They also underscore that smaller is the screen higher is the adverse impact. (Times of India, $28^{\text {th }}$ Sept 2020) ${ }^{\mathbf{1 3}}$.

In another news item (Times of India, October $1,2010)^{\mathbf{1 4}}$, doctors have opined that Work from Home(WFH) is causing stiff neck and frozen shoulders to people who are using the online platform for long duration. Doctors advise that people should take small breaks after every hour of online work.

\section{Literature Review}

In an article on the stress caused due to the shift of teaching-learning to Online virtual mode, author (Moawad, R.A.2020)15 found that students are mostly stressed about the examinations during the pandemic as they are unsure how they will be able to cope with online examinations. New process of examination and various technical hurdles that can pop up creates uncertainty in the mind of the students. This research has been conducted in one university in Saudi Arabia. The author advises educators and academicians to design their course in such a manner that a student can easily grasp it and will not be stressed for the examination. Universities should also deliberate on the process of examination and the type of questions that should be asked in the online mode of examination.

In an article (MacIntyre PD et.al,2020)16 authors describe the kind of stress that language teachers across the globe are facing due to the online teaching and their coping ways. Based on the survey of 600 teachers, the authors have found that teachers who deal with the stress in positive manner are more happy compared to those who tried to avoid the stress. Correlations showed that positive psychological outcomes (well being, health, happiness, resilience, and growth during trauma) correlated positively with approach coping and negatively with avoidance coping. The author underscores that teaching is a stressful job and complete dependence on online platform for teaching has made it more stressful.

In a research paper by (Klassen,R. et.al,2013)17, it is highlighted that work stress for teachers is multifaceted and varies from culture to culture. Author mention at the beginning of the article that teaching is one of the most stressful profession. One has to remain updated with the subject and also the changing aspirations of the students. A teacher has to not only take care of the needs of the best students but also those who are laggards. Physically and mentally challenged students pose even bigger responsibility on the teachers. These stress arises from behaviour of the students and also from the nature of the work. Teaching students and also handling the administrative tasks in the educational institutions subject the teachers to a lot of workplace stress and those have lead to several physical and mental health outcomes. Ability to handle stress proactively increases the commitment towards the organization and also reduces teacher attrition. A belief of self efficacy goes a long way in reducing the teacher's stress. Therefore, there is a need for proper training and mentoring of young teachers before they are given the task of class room teaching. Such training should also include how to handle students in the class room to ensure discipline in the class room and also better learning by the students. This research also finds out that the stress is more prominent among the new generation teachers than the old generation teachers. Aged teachers are more ready to cope with the changing needs of the teaching.

In a research paper by (Hall,J.C,et.al,2013)18 the authors show how racism and sexism are stressors for African American women in the workplace. Apart from inequality, these women also face discrimination on grounds of diversity. These women have used their emotions and problem solving as a method of coping with such stress at their workplace. Authors underscore the fact that gender itself is a cause of stress at work place. Women face higher discrimination and higher work related challenges and hence are more stressed than the men. Over above this stress due to gender, African-Americans face discrimination and unequal treatment at the workplace due to their color. On the one hand USA is the boiling pot of all talent and diversity and that is the reason why it has been the most developed country of the world. On the other hand, the undercurrent of discrimination is still there and specific category of people face the stress for such discrimination. In short, the article points that gender and race has a direct relationship with work related stress.

In a research paper (Limm.H,,et.al,2011)19, the authors have focused on how organizational stress has lead to several physical and mental health issues to their employees. They also mentioned how the Stress Management Intervention (SMI) using effort-reward imbalance (ERI) model can be helpful it reducing 
physical and emotional stress among the employees of an organization.

(Roizen, M.\&Roach, K.W,2010)20 in their article mentioned how excessive stress at workplace affects the employees physically and mentally. Moreover such stress adversely affects the efficiency and effectiveness of the employees. Therefore, the employers should take necessary care to ensure that the causes of stress at the work place are eliminated. Hygiene condition at the workplace is one of the important contributors to the stress of the workers. The authors also refer to the improvement in quality of service in hospitals and reduction in defects in manufacturing set-ups by alleviating the stress of the workers.

In a research paper (Largo,E,et.al,1974)21, the authors have focused on how nature helps employees to be stress free and how it increases their efficiency. A greener neighborhood and a natural work environment helps in maintaining the positive spirit of the employees. Noise and clutter at the work place hinders efficiency and quality of work. Green environment should be pursued by all employers for the benefit of the employees.

In an article (K. Ong,2019)22, the author mentions how stress level at workplace depends on the gender of their supervisors or bosses. The signs and symptoms of stress among female workers are found to be more when they are working under female supervisors as compared to that of a male supervisor. Unlike the female workers their male counterpart is found to be more stressed under a male boss. This article also throws light on personality types and coping mechanism. It shows that people who are confident and are sure of their capability to do a job are less stressed than the opposite types. People who have faced difficult situations in their life are more at ease in coping with the changes that has come with the onset of the pandemic.

(Bailey, J, et.al. 2020) 23 in their article talks about the strategic plans needed to open the school in a manner that is safe for students, teachers and other stake holders. The author mentions that in a very short period of time teachers have been able to provide teaching to the students on the online platform though it is not that effective as it is in a classroom. Sooner or later, schools have to open and planning is necessary for the same. It is not only the school administrators who are to be involved in the process, others stake holders also should contribute to the ideas in their own way. Parents, community, health department and regulators must give their input for proper preparation.
In a research paper (Kelly, A.P. \& Columbus, R, 2020) 24 , authors throws light on how the educational institutions in USA have faced the huge financial losses due to the shift to virtual mode of teaching. There is also looming uncertainty as to when the educational institutions can bounce back to the normalcy. A major source of revenue for many universities in USA was the fees received from foreign students. With the fear of pandemic spreading in USA and other European countries, most students have either canceled their plans to study abroad or have deferred it till good times returns. Though this article is written with the USA in sight, the narrative is equally relevant to India and Indian educational Institutes and Universities. New admissions are down and regular students are also not making the fee payments promptly. Due to this educational institutes are facing financial constraints and are making partial payment of salary to the teachers and other support staffs. This is another reason why teachers are stressed.

In a research paper (Kyaw- Myint, S.M \& Strazdins, 2015) 25 authors mentions how mental stress or psychological stress is a part of occupational stress and that it not only affects the blue-collar workers but also the white-collar workers (Satpathy \& Samanta, 2020). This research has been undertaken in Australia and draws upon the feedback from people working in shop floor and offices to know how they are affected by the stress arising out of their job. It is found that physical and mental stress are integral to occupations and all types of workers and employees can suffer from such stress.

\section{RESEARCH GAP}

While lot of research has been done in the area of work related stress, technology induced stress and virtual workplace related stress, not much work has been done with regard to the stress related to education sector. Teaching is a very stressful profession and recent shift to online teaching has added to the stress. It is a paradigm shift from the traditional way of teaching-learning and both the teacher and the students are trying to cope with the new online platform. In this paper we tried to find out the prevalence of stress because of online teaching-learning and its physical/mental manifestation on the teachers and the students.

\section{OBJECTIVES}

1. To find out if the users of online teaching-learning are physically/mentally stressed 
2. To find out the physical manifestations of stress among the users of the online teaching- learning.

\section{METHODOLOGY}

This is an exploratory research to find out if teachers/students are stressed because of use of online teaching/learning and what are the different aspects of that stress. The population for the research was all the teachers and students in private schools and colleges. We limited the research to private sector as most of them have shifted to some form of online teaching. We planned to collect data from nearly 250 respondents (Students -200 and Teachers-50) who are reading or teaching in any class from primary to post graduation.

Questionnaire was used to collect data. Google form was created to easily collect the data from the respondents. Important variables on which information was collected are - Device used for online learning/teaching, hours of usage, types of stress caused (physical/mental) and manifestation of physical stress (head ache, neck ache, backache etc).

Cross Tabulation and percentage tables were used to analyse data. Quantitative data were used to describe the phenomenon of stress caused due to online teaching/learning.

\section{DATA ANALYSIS AND FINDINGS}

277 respondents participated in the survey. Out of them 241 are students and 36 are teachers. In terms of gender distribution of the respondents $127(53 \%)$ are Females and 114(47\%) are Males .The composition of the students from different class is shown below. Responses were mostly from 11 th-12th class students (31\%) and Undergraduates (58\%). School students (9\%) and Post-graduates (2\%) participated in the survey.

\section{Table-1 : Profile of Student Respondents}

\begin{tabular}{|l|l|l|}
\hline Class of the student & Number & Percentage \\
\hline 1st-4th & 2 & $1 \%$ \\
\hline 5 th-6th & 3 & $1 \%$ \\
\hline 7 th-8th & 5 & $2 \%$ \\
\hline 9th-10th & 11 & $5 \%$ \\
\hline 11 th-12th & 74 & $31 \%$ \\
\hline $\begin{array}{l}\text { Undergraduate } \\
\text { courses }\end{array}$ & 139 & $58 \%$ \\
\hline $\begin{array}{l}\text { Post Graduate } \\
\text { courses }\end{array}$ & 6 & $2 \%$ \\
\hline Other & 1 & $0 \%$ \\
\hline Total & 241 & $100 \%$ \\
\hline
\end{tabular}

Source : Original Data
In terms of the usage pattern of devices for online classes $34.1 \%$ use only Mobile, $26.8 \%$ used only Laptop and $17.8 \%$ used both Mobile and Laptop. Use of Desktop for Online classes is only $2.1 \%$.

Table-2 : Device Usage Pattern for Online classes

\begin{tabular}{|l|l|l|}
\hline Device Used & Number & Percentage \\
\hline Mobile & 94 & $34.1 \%$ \\
\hline Laptop & 74 & $26.8 \%$ \\
\hline Laptop; Mobile & 49 & $17.8 \%$ \\
\hline Desktop & 5 & $1.8 \%$ \\
\hline Desktop; Mobile & 5 & $1.8 \%$ \\
\hline $\begin{array}{l}\text { Desktop; Laptop; } \\
\text { Mobile }\end{array}$ & 4 & $1.4 \%$ \\
\hline Laptop; Mobile; Tab & 2 & $0.7 \%$ \\
\hline Mobile; Tab & 2 & $0.7 \%$ \\
\hline Others & 2 & $0.7 \%$ \\
\hline Tab Laptop; & 2 & $0.7 \%$ \\
\hline $\begin{array}{l}\text { Desktop; } \\
\text { Mobile; Others }\end{array}$ & 1 & $0.4 \%$ \\
\hline Laptop; Tab & 1 & $0.4 \%$ \\
\hline
\end{tabular}

Source : Original Data

In this research our main focus was to find out if teachers and students are stressed because of using digital platform in teaching-learning. To our question, if they feel tired after completion of all classes $90 \%$ responded in affirmative and only $10 \%$ responded in negative. To the question if Internet connectivity is a major cause of stress, $46 \%$ strongly agreed and $45 \%$ agreed. This finding validates our hypothesis that, Internet (signal strength and data limits) is one of the reasons that causes stress. We also tried to find out if people who use digital platform for learning are stressed physically, mentally or both.

\section{Diagram-1 : Type of Stress}

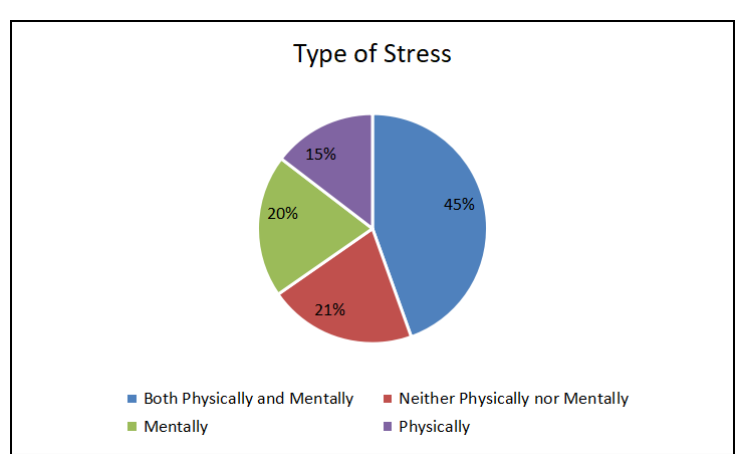

Source : Original Data

When we tried to find out in what way they are stressed, nearly $80 \%$ said they are stressed either physically or mentally or both . The other important finding of this research is that nearly $45 \%$ people said that they are stressed both physically and 
mentally. Only 20\% said they were neither physically nor mentally stressed.

The other aspect that we tried to look into is about the manifestation of stress. It is found that nearly $25 \%$ of the respondents suffer singular pain (headache, vision fatigue, neck pain, back pain and other pain) and rest $75 \%$ suffer from combination of these pains.

We also tried to find out if the size of the screen has a relationship with the stress caused.

Table-3 : Device-wise Stress Percentage

\begin{tabular}{|l|l|l|l|}
\hline $\begin{array}{l}\text { Devices } \\
\text { Used }\end{array}$ & Stress-No & Stress-Yes & Percentage-Yes \\
\hline $\begin{array}{l}\text { Desktop; } \\
\text { Laptop; } \\
\text { Mobile }\end{array}$ & 1 & 4 & $80 \%$ \\
\hline $\begin{array}{l}\text { Desktop; } \\
\text { Mobile }\end{array}$ & 2 & 4 & $67 \%$ \\
\hline Laptop & 7 & 86 & $92 \%$ \\
\hline $\begin{array}{l}\text { Laptop; } \\
\text { Mobile }\end{array}$ & 10 & 49 & $83 \%$ \\
\hline Mobile & 13 & 85 & $87 \%$ \\
\hline
\end{tabular}

Source : Original Data

But when we look at the data at the above table, it shows that there is high percentage of respondents are stressed irrespective of the type of device used.

\section{LIMITATION OF THE STUDY}

There are many reasons that cause stress to teachers and students. We only looked at the physical and mental stress that is caused due to use of online platform. We also did not include the teachers and students studying in Government schools as most of the Government schools have not been able to shift to online teaching-learning $26 \&$ 27. While government launched various online platforms like Swayam, Diksha, e-PG Pathshala etc for the continuity of learning, a major segment of students have not been able to access these facility. The primary reason being low access to device and internet among the teachers and students in this segment.

Students who filled up the questionnaire are mostly belong to 11 th-12th class or undergraduate courses. We could not get proportional responses from all classes and all age groups.

\section{CONCLUSION}

Corona pandemic forced teachers and students to move to online mode of teaching-learning when they were least prepared. Though devices for online teaching-learning are available with most of the teachers and students, access to uninterrupted high speed internet is not available to everyone. Work from home is a challenge as it is difficult to separate work and family life in home environment. Most of the people might not even be having needed furniture to work on, as they normally have at schools and colleges. Teachers and students are managing from home with whatever facility is available. Communication is easy in a physical classroom and that facilitates teaching-learning. In an online platform, both the teacher and the students have to put in extra attention and effort for teaching-learning. What makes things more challenging is the absence of good digital infrastructure, particularly internet connection. All these hurdles have caused stress to both the teachers and the students. They are stressed both physically and mentally. Many reports from hospitals also suggest that such cases are rising. Doctors advise meditation, physical exercise and reduced digital exposure to avoid such stress.

\section{REFERENCES}

[1] "India under lockdown: Here's what will remain open and what".TIMESOFINDIA.COM | Mar 30 , 2020, http://timesofindia.indiatimes.com/articleshow/ 74798407.cms?utm_source $=$ contentofinterest\& utm_medium $=$ text\&utm_campaign $=$ cppst

[2] 'Lockdown extended till May 3': Modi's speech full text, TIMESOFINDIA.COM | Apr 14, 2020,https://timesofindia.indiatimes.com/india/1 ockdown-extended-till-may-3-modis-speech-ful 1-text/articleshow/75135470.cms

[3] Indian economy to struggle with effects of virus through 2020"TIMESOFINDIA.COM

Nov19,,http://timesofindia.indiatimes.com/articl eshow/79304753.cms?utm_source $=$ contentofint erest\&utm_medium $=$ text\&utm_campaign $=$ cpps $\mathrm{t}$

[4] "Digital divide shadows post pandemic education". The Hindu, Delhi Ed, $9^{\text {th }}$ September 29, 2020.9.29

[5] "Bonda Teen Treks $5 \mathrm{~km}$ daily to attend e-classes" ,The Times of India, Bhubaneswar Ed, $28^{\text {th }}$ September 17, 2020.

[6] "Not giving gadgets, net to poor for online classes, digital apartheid"The Times of India, Bhubaneswar Ed, 19th September, 2020. 
[7] "Remote Learning may have drawbacks, but some students are thriving in zoom school", The Times of India, $1^{\text {st }}$ October 18,2020 , Bhubaneswar Ed.

[8] "Remote realities: Children with disabilities bear the brunt of online education during pandemic", The New Indian Express , 10th October 2020

[9] "In RS Congress bats for policy to address mental health issues". The Times of India, Bhubaneswar Ed, 28 ${ }^{\text {th }}$ September 16, 2020.

[10] "COVID-19: How smart classrooms are transforming India's education system" , Financial Times, $5^{\text {th }}$ May,2020.

[11] "How Principals prepared for their toughest test ever"The Times of India, Bhubaneswar Ed, $28^{\text {th }}$ September, 2020.

[12] "Risue Songs, chats plague teachers during e-classes", The Times of India, Bhubaneswar Ed, 22nd September, 2020.

[13] "Eye Strain epidemic risk for kids and WFH employees", The Times of India, Bhubaneswar Ed, $28^{\text {th }}$ September 29, 2020.

[14] "WFH has left employees with still neck and frozen shoulder". The Times of India, $1^{\text {st }}$ October 1, 2020, Bhubaneswar Ed.

[15] Moawad, R.A. (2020). Online Learning during the COVID- 19 Pandemic and Academic stress in University Students. Revista Romaneasca pentru Educatie Multidimensionala, 12(1Sup2), xx-xx. https://doi.org/10.18662/rrem/12.1sup1/

[16] MacIntyre PD, Gregersen T, Mercer S. Language teachers' coping strategies during the Covid-19 conversion to online teaching: Correlations with stress, wellbeing and negative emotions. System.

2020;94:102352.doi:10.1016/j.system.2020.102 352

[17] Klassen,R,et al.(2013), 'Preservice teachers' work stress, self-efficacy, and occupational commitment in four countries", European Journal of Psychology of Education , December 2013, Vol. 28, No.4 (December 2013), pp. 1289-1309,

https://www.jstor.org/stable/23580909,

[18] Hall,JC \.C.et.al.(2012),"Black Women Talk About Workplace Stress and How They Cope", Journal of Black Studies, MARCH 2012, Vol. 43, No. 2 (MARCH 2012), pp. 207-226, https://www.jstor.org/stable/23215207?seq=1
[19] Limm. H, et.al.(2011)"Stress management interventions in the workplace improve stress reactivity: a randomised controlled trial", Occupational and Environmental Medicine, February 2011, Vol. 68, No. 2 (February 2011), pp. 126-133,

\section{https://www.jstor.org/stable/25802154}

[20] Roizen, M. \& Roach, K.W(2010), 'Wellbeing in the workplace", British Medical Journal , 29 May 2010, Vol. 340, No. 7757 (29 May 2010), pp.

1150-1151,https://www.jstor.org/stable/407021 $\underline{26}$

[21] Largo, E, et.al.(1974), "The Effects of Nature Contact at Work on Employee Stress and Health". Public Health Reports (1974-) , MAY/JUNE 2011, Vol. 126, Supplement 1: Healthy People in a Healthy Environment (MAY/JUNE 2011),pp. 124-130, https://www.jstor.org/stable/41639273

[22] Ong, K.(2019),"5 Things You Need to Know About Stress", Women of Color Magazine, Vol. 19, No. 2 (FALL 2019), pp. 80-93,https://www.jstor.org/stable/26924281?se $\mathrm{q}=1$

[23] Bailey, J,et.al.(2020),"A Blueprint for Back to School", American Enterprise Institute, http://www.jstor.com/stable/resrep24606.

[24] Kelly, A.P. \& Columbus.R(2020),"College in the Time of Coronavirus CHALLENGES FACING AMERICAN HIGHER EDUCATION". American Enterprise Institute,https://www.jstor.org/stable/resrep2535 8

[25] Kyaw-Myint,S.M\& Strazdins (2015) , "Health of People, Places And Planet: Reflections" based on Tony McMichael's four decades of contribution to epidemiological understanding, edited by Colin D. Butler, Jane Dixon and Anthony G. Capon, published 2015 by ANU Press, The Australian National University, Canberra, Australia.

[26] "New study shows online teaching isn't working for govt-school students, exacerbating existing learning gaps", The Financial Express | November 20, 2020

[27] "90 lakh govt college students can't access online lessons, report states, urges aid" The Print, 28 July, 2020

[28] TK Satpathy, S Samanta, Influence of Spiritual Intelligence on human psychology- a review, Wutan Huatan Jisuan Jishu 16 (X) (2020) 